\title{
Control de constitucionalidad y delegación legislativa
}

\author{
Rodrigo Sánchez Brígido \\ Universidad Nacional de Córdoba \\ Universidad Blas Pascal, Córdoba
}

Resumen: Los sistemas constitucionales contemporáneos suelen, en casos excepcionales, conferir al Poder Ejecutivo facultades legislativas. De acuerdo a la Constitución Argentina, por ejemplo, la delegación debe efectuarse en materias circunscriptas a asuntos de administración o emergencia pública, por cierto tiempo, y mediante una ley que fije las bases de la delegación. Un interrogante natural, en ese marco, es cómo proceder cuando las bases de la ley delegante, aun si circunscriptas a asuntos de administración o emergencia pública y por cierto tiempo, son demasiado genéricas o indeterminadas. La Excma. Corte Suprema ha propuesto, siguiendo los lineamientos de la jurisprudencia norteamericana del intelligble standard, una respuesta a ese interrogante: ha fijado una doctrina acerca de cómo juzgar la constitucionalidad de esos decretos. El ensayo intenta mostrar que la doctrina de la Corte argentina en realidad propone dos reglas diferentes sobre cómo juzgar la constitucionalidad de esos decretos. El inconveniente estriba en que solo una de esas reglas es relevante para resolver el problema de qué hacer con las leyes delegantes demasiado genéricas, y esa regla es inaceptable por varias razones. Se efectúan, finalmente, algunas sugerencias acerca de cómo proponer una regla aceptable.

Palabras clave: Delegación legislativa - Standard inteligible - Bases genéricas o indeterminadas - Política legislativa - Interpretación restrictiva 
Los sistemas constitucionales contemporáneos suelen conferir al Poder Ejecutivo facultades propias de otros poderes, como las facultades legislativas. Las delegaciones de facultades suelen justificarse en base a que muchos problemas no pueden ser atendidos por el procedimiento ordinario de sanción de las leyes, por su complejidad técnica y el tiempo que insumen. La delegación es vista no obstante, a la luz del principio de división de poderes, como excepcional. El problema radica en que no siempre resulta claro el alcance de esas excepciones.

La jurisprudencia suele encargarse, cuando no hay una norma explícita sobre el particular, de ir moldeando el alcance de esas excepciones. En los Estados Unidos, por ejemplo, la Corte de ese país ha dejado sentada la doctrina según la cual no basta que el Congreso manifieste su voluntad de delegar cierta atribución. Debe fijar además un patrón o principio inteligible al que la persona o cuerpo autorizado tiene que conformarse ${ }^{1}$.

En la República Argentina existe una norma explícita. La reforma constitucional de 1994 fijó de modo expreso, en efecto, el alcance de las excepciones. El art. 76 de la Constitución Nacional permite la delegación solo por vía de excepción y cumpliendo ciertas pautas. Debe existir una ley del Congreso en la que se efectúe la delegación, a la que llamaré "ley delegante". Y el Poder Ejecutivo puede ejercer las facultades delegadas mediante el dictado de decretos, a los que llamaré "decretos delegados", siempre que se enmarquen en la ley delegante. Dicha ley debe reunir tres requisitos: la delegación debe restringirse a materias determinadas de administración o de emergencia pública, con plazo fijado para su ejercicio, y debe indicar las bases de la delegación ${ }^{2}$.

${ }^{1}$ Loving v. United States, 517, U.S. 748, 758 [1996]. Las primeras enunciaciones de esta doctrina pueden rastrearse en Panamá Refining Company v Ryan, 293 U.S., 398, y Schecter Poultry Corp. V United States, 295 U.S., 495.

${ }^{2} \mathrm{El}$ art. 76 dispone: "Se prohíbe la delegación legislativa en el Poder Ejecutivo, salvo en materias determinadas de administración o de emergencia pública, con plazo fijado para su ejercicio y dentro de las bases de la delegación que el Congreso establezca. La caducidad resultante del transcurso del plazo previsto en el párrafo anterior no importará revisión de las relaciones jurídicas nacidas al amparo de las normas dictadas en consecuencia de la delegación legislativa". 
La norma constitucional no terminó de despejar, por cierto, la controversia sobre el alcance de las excepciones. Así, por ejemplo, no es claro qué debería entenderse por "materias de administración" o "emergencia pública". Tampoco es claro cuál es el tiempo razonable de delegación, entre otros inconvenientes.

Uno de los problemas más acuciantes, en ese marco, es cómo proceder cuando las bases de la ley delegante, aun si circunscriptas a asuntos de administración o emergencia pública y por cierto tiempo, son demasiado genéricas o indeterminadas. Si fuera admisible ese tipo de indeterminación, en efecto, parece que el Congreso podría dar una autorización al Poder Ejecutivo casi ilimitada para legislar. Dicho de modo simple: dada una ley delegante que faculta al Ejecutivo a dictar un decreto delegado en un asunto determinado de administración, por cierto tiempo, pero con bases excesivamente laxas, la ley delegante se acercaría mucho a una ley "en blanco", que pondría en duda el carácter excepcional del ejercicio de facultades legislativas por el Poder Ejecutivo.

La Corte Suprema de la Nación Argentina ha fijado recientemente una posición sobre ese problema. En "Colegio Público de Abogados" (Fallos 331:2406) estableció, en efecto, que los decretos delegados deben satisfacer ciertos recaudos especiales cuando las bases sean demasiado genéricas e indeterminadas.

En este ensayo quiero examinar brevemente esa doctrina de la Corte argentina. Intentaré mostrar que la doctrina es confusa, pues el tribunal ha propuesto distintos criterios sobre cuándo la doctrina es aplicable y sobre qué recaudos deben satisfacer los decretos delegados para ser constitucionales. Sugeriré luego que, si se despeja esa confusión inicial, la doctrina puede ser vista como proponiendo dos reglas diferentes sobre cómo juzgar la constitucionalidad de decretos delegados. E1 inconveniente es que solo una de esas reglas es relevante para resolver el problema de qué hacer con las leyes delegantes demasiado genéricas. $Y$ esa regla es inaceptable por varias razones. No constituye por ello un avance para el problema que pretendía resolver. Esa tarea está todavía

$\mathrm{El}$ art. 100 inc. 12, por su parte, exige que los decretos sean refrendados por el Jefe de Gabinete de Ministros y sometidos al control de la Comisión Bicameral Permanente del Congreso. 
por hacerse. Propongo finalmente algunas sugerencias muy breves sobre cómo deberían sortearse algunos obstáculos a la hora de realizar esa tarea.

Aunque el ensayo está circunscripto a la doctrina de la Corte argentina, creo que será de utilidad para extraer algunas conclusiones generales sobre cualquier intento por fijar límites materiales a la delegación legislativa.

\section{E1 caso}

En "Colegio Público de Abogados" se discutía la constitucionalidad del decreto delegado 1204/01, por el que se pretendía relevar a los abogados del Estado Nacional de la obligación de inscribirse en la matrícula fijada por el Colegio de Abogados de la Capital y de pagar un derecho fijo en actuaciones judiciales establecido por la ley de creación de ese ente. E1 Poder Ejecutivo sostuvo, en lo que interesa aquí, que ese decreto era válido en tanto había sido dictado en base a la delegación de facultades legislativas contenida en el art. 1 inc. "f" de la ley 25414. Esta norma autorizaba al Poder Ejecutivo a ejercer facultades legislativas en estos términos:

Con el objeto exclusivo de dar eficiencia a la administración podrá derogar total o parcialmente aquellas normas específicas de rango legislativo que afecten o regulen el funcionamiento operativo de organismos o entes de la administración descentralizada, empresas estatales o mixtas, o entidades públicas no estatales, adecuando sus misiones y funciones; excepto en materia de control, penal o regulatoria de la tutela de intereses legítimos o derechos subjetivos de los administrados, y con respecto al Instituto Nacional de Servicios Sociales para Jubilados y Pensionados.

Para evaluar la constitucionalidad del decreto, la Corte Suprema examinó primero los propósitos que la reforma constitucional persiguió (básicamente, atenuar el sistema presidencialista) y consideró que los constituyentes adoptaron un modelo de delegación legislativa tomado del derecho estadounidense. Ese modelo estaría basado, según la Corte 
Suprema, en la doctrina del intelligible standard, es decir, la idea según la cual la ley delegante debe fijar un patrón claro e inteligible de delegación. En ese sentido, la Corte Suprema sostuvo que, frente al uso de facultades delegadas de manera indeterminada, hay dos caminos posibles: "o bien anular la ley delegatoria por no fijar un lineamiento inteligible, o bien interpretar muy restrictivamente la eficacia de la delegación y, por lo tanto, limitar las posibilidades de que el acto en cuestión pueda encontrar apoyo en la delegación excesivamente vaga". Este último es el camino que predominantemente habría seguido la Corte Suprema de los Estados Unidos y, dado que dicho modelo es el que opera como fuente de la reforma constitucional argentina, es el camino que, según la Corte Suprema argentina, debe seguirse aquí3.

Pues bien, la doctrina que la Corte Suprema dejó establecida para los decretos delegados fue expresada en los siguientes términos:

a partir del sentido que se buscó asignar al texto constitucional argentino y de las características del modelo seguido, se desprende que: $1^{\circ}$ ) la delegación sin bases está prohibida y $2^{\circ}$ ) cuando las bases estén formuladas en un lenguaje demasiado genérico e indeterminado, la actividad delegada será convalidada por los tribunales si el interesado supera la carga de demostrar que la disposición dictada por

${ }^{3}$ La Corte ya había empleado la idea de un patrón inteligible antes de la reforma constitucional en Fallos: 246:345. La Corte sostuvo allí "Que tampoco es admisible el argumento relativo a la existencia, en el caso, de una inválida delegación de facultades legislativas en el Poder Ejecutivo. En efecto, tratándose de materias que presentan contornos o aspectos tan peculiares, distintos y variables que al legislador no le sea posible prever anticipadamente la manifestación concreta que tendrán en los hechos, no puede juzgarse inválido, en principio, el reconocimiento legal de atribuciones que queden libradas al arbitrio razonable del órgano ejecutivo, siempre que la política legislativa haya sido claramente establecida (ver sobre este punto: Cámara de Diputados, 1946, t. XI, p. 828). Y ello, habida cuenta de que, en tales supuestos, ese órgano no recibe una delegación proscripta por los principios constitucionales, sino que, al contrario, es habilitado para el ejercicio de la potestad reglamentaria que le es propia (art. 86 , inc. $2^{\circ}$ ), cuya mayor o menor extensión depende del uso que de la misma potestad haya hecho el Poder Legislativo..." 
el Presidente es una concreción de la específica política legislativa que tuvo en miras el Congreso al aprobar la cláusula delegatoria de que se trate. Esta conclusión resulta insoslayable apenas se advierte que la delegación sin bases está prohibida precisamente porque bloquea la posibilidad de controlar la conexión entre la delegación del Congreso y la actividad desplegada por la autoridad administrativa. Así, por ser amplia e imprecisa, la delegación no confiere atribuciones más extensas, sino, al revés, a mayor imprecisión, menor alcance tendrá la competencia legislativa que podrá el Ejecutivo ejercer válidamente. En otros términos, el principio constitucional contrario al dictado de disposiciones legislativas por el Presidente tiene, en el plano de las controversias judiciales, una consecuencia insoslayable: quien invoque tales disposiciones en su favor deberá al mismo tiempo justificar su validez, o sea, demostrar que se hallan dentro de alguno de los supuestos excepcionales en que el Ejecutivo está constitucionalmente habilitado. En materia de delegaciones legislativas, dicha carga se habrá cumplido si los decretos, además de llenar los diversos requisitos constitucionales ya referidos, son consistentes con las bases fijadas por el Congreso (conforme artículos 76 y 100, inciso 12 de la Constitución Nacional). Por consiguiente, la defensa del decreto legislativo tendrá mayores probabilidades de éxito cuanto más claras sean las directrices de la ley delegatoria y menores, cuando ellas consistan solo en pautas indeterminadas.

La Corte declaró entonces la inconstitucionalidad del decreto porque no satisfizo esa doctrina. Dijo así que

la parte demandada ha actuado con una lógica diametralmente contraria a la que, según el análisis hecho más arriba, subyace a las reglas constitucionales sobre la delegación legislativa: en primer lugar, se apoyó en una lectura sumamente amplia e indeterminada de la ley 25414 que, si es tomada estrictamente, habilitaría al Presidente para derogar prácticamente cualquier ley vigente $\mathrm{y}$, en segundo término, en lugar de ofrecer una demostración de que, pese a ello, las disposiciones dictadas por el Ejecutivo formaban parte de la política que efectivamente adoptó el Congreso en el artículo 
1.f. de la ley 25414, se limitó a solicitar una aplicación mecánica del texto legal, en la versión vaga e inexpresiva por ella misma propuesta.

La doctrina de la Corte que se acaba de reseñar puede ser examinada a la luz de varios criterios. Así, uno podría considerar si efectivamente la jurisprudencia estadounidense sostiene lo que la Corte dice que sostiene $^{4}$, o si ello es en algún sentido relevante ${ }^{5}$. Pondré de lado esas cuestiones porque, a mi manera de ver, existe un problema preliminar: no es claro cuál es el alcance de la doctrina sentada en "Colegio Público de Abogados".

\section{Distintos criterios sobre la aplicabilidad}

El primer problema a la hora de determinar el contenido de la doctrina es cuándo es aplicable. El modo habitual en que la postura ha sido receptada es a través del dictum de la Corte según el cual "cuando las bases están formuladas en un lenguaje demasiado genérico e indeterminado, la actividad delegada será convalidada si ...". En otras palabras, normalmente se entiende que la doctrina se activa cuando las bases de la ley delegante son demasiado genéricas e indeterminadas. Recién allí puede exigirse a los decretos que satisfagan ciertos recaudos adicionales. Pero no es en absoluto claro que la Corte haya dicho solamente eso, ni tampoco qué ha dicho exactamente al decirlo.

${ }^{4}$ Hay quienes sostienen que la correcta interpretación del art. 76 no debe apelar, al considerar su fuente, al derecho estadounidense sino al derecho español. Véase Salvadores de Arzuaga, Carlos, "Delegación legislativa: fuente e interpretación", en LA LEY 27/03/2009, 4 - LA LEY 2009-B, 538.

${ }^{5}$ Para una visión negativa general de la relevancia en materia de delegación legislativa anterior a la reforma constitucional, véase Barraza, Javier Indalecio, "La delegación legislativa" Publicado en: LA LEY 21/09/2011, 1 - LA LEY 2011-E, 1002: "Resulta paradójico: Se estudian los fallos de la Corte Suprema estadounidense para extraer de ellos principios jurídicos generales, aunque estos principios han sido elaborados por políticos, en el marco de disputas políticas y con objetivos políticos. No obstante, en la Argentina estos fallos son reseñados sistemáticamente". 
Así, la Corte sostiene que "por ser amplia e imprecisa, la delegación no confiere atribuciones más extensas, sino, al revés, a mayor imprecisión, menor alcance tendrá la competencia legislativa", y también que "la defensa del decreto legislativo tendrá mayores probabilidades de éxito cuanto más claras sean las directrices de la ley delegatoria y menores, cuando ellas consistan solo en pautas indeterminadas". Además, la Corte también fustiga al Estado Nacional por proponer una aplicación mecánica de la ley "en la versión vaga e inexpresiva por ella misma propuesta".

Como se ve, la Corte califica a las bases de la ley delegante que activan la aplicación de la doctrina sucesivamente como "demasiado genéricas o indeterminadas", "más o menos imprecisas", "más o menos amplias", "poco claras", y "vagas". Se trata de nociones bien distintas, sin embargo.

Considérese la vaguedad. En un enfoque filosófico standard la vaguedad es vista como una propiedad de los conceptos expresados en lenguajes no formales. Hay distintas concepciones filosóficas de la vaguedad. Así, en sentido estricto, se considera que un concepto vago es tal si tiene una zona de indeterminación, límites imprecisos, y si está sujeto a la paradoja del sorites $^{6}$. En un sentido más amplio, propio de la teoría jurídica anglosajona, un concepto vago es aquel en relación al cual hay dudas, respecto de ciertos items en el mundo, acerca de si quedan dentro del alcance del concepto (duda que puede no deberse, por ejemplo, a que estén sujetos a la paradoja mencionada) ${ }^{7}$. En cualquier versión, no obstante, los conceptos vagos tienen instancias claras de aplicación. De manera que un concepto puede ser vago pero claro. Y es también posible que haya conceptos vagos y oscuros. La vaguedad y la claridad pueden estar instanciadas una independientemente de la otra. Eso muestra que se trata de dos nociones diferentes.

${ }^{6}$ Keefe, Rosanna, Theories of Vagueness, Cambridge University Press, Cambridge, 2003, pág. 6.

${ }^{7}$ Esa es en líneas generales la idea de textura abierta de Hart. Cfr. Hart, H.L.A., The Concept of Law, Clarendon Press, Oxford, 1994, pág. 123. 
Además, la vaguedad en los sentidos filosóficos destacados es distinta no solo de la claridad, sino también de las otras nociones que la Corte emplea, esto es, la indeterminación, amplitud, carácter genérico o imprecisión. Una expresión o concepto puede ser amplio, por ejemplo, y la amplitud deberse a razones distintas de la vaguedad.

Más aun, las nociones de indeterminación, amplitud, imprecisión, o carácter genérico son a su vez muy diferentes entre sí, y diferentes también de la idea de claridad.

La Corte, en suma, ha empleado nociones muy distintas para caracterizar las bases de la ley delegante y, en definitiva, para establecer cuándo un decreto delegado es (in)constitucional. Eso origina cierto desconcierto, por la obvia razón de que hay conceptos que son vagos pero claros y amplios, no vagos y claros y determinados, etc.

Es probable, sin embargo, que la Corte haya querido referirse, al mencionar todas esas nociones, a dos situaciones diferentes.

La primera situación, a mi manera de ver, es aquella en que las bases son tales que dejan dudas acerca de si un decreto delegado constituye un ejercicio de la facultad conferida. Eso puede deberse a la vaguedad en sentido filosófico, por ejemplo. Pero puede deberse a la vaguedad en sentido no filosófico, es decir, la que se emplea para mencionar la imprecisión en general ${ }^{8}$. Puede deberse también a la oscuridad de la ley delegante. En otras palabras, la vaguedad, la oscuridad, y la indeterminación parecen nociones empleadas por la Corte para referirse a distintas fuentes de imprecisión en el sentido señalado, es decir, fuentes de dudas acerca de si un decreto delegado encuadra dentro de las bases de la ley delegante.

La segunda situación es diferente. Puede no haber dudas acerca de si un decreto encuadra en las bases. Por ejemplo, la ley juzgada en Colegio Público de Abogados autorizaba al Ejecutivo a derogar leyes para "dar eficiencia" a la administración. Esa ley delegante puede perfectamente no dejar dudas acerca de si una derogación de una ley en particular hace a la Administración más eficiente. No es descabellado

${ }^{8}$ Cfr. Endicott, Timothy, Vagueness in Law, Oxford University Press, Oxford, 2003, pág. 32 y siguientes. 
pensar que la derogación de la ley que obligaba al pago de las tasas por los abogados del Estado (el asunto que era juzgado en ese caso) sí hace a la administración más eficiente, en el sentido de que le permite aprovechar los recursos al máximo dado los objetivos que la administración tiene. El problema no es la duda, sino que las bases son demasiado amplias, en el sentido de que se acercan demasiado a una ley "en blanco". En otras palabras, debe distinguirse entre una delegación que deja dudas acerca de qué se delega, y otra que no deja dudas pero es excesiva. Este último es el otro sentido involucrado detrás de las ideas de "demasiado indeterminada", "genérica", "vaga", etc., que la Corte emplea.

En definitiva, una manera de interpretar la doctrina de la Corte, que despeja el desconcierto sobre cuándo se activa la doctrina, es que se activa en dos situaciones distintas: cuando las bases de la ley delegante son tales que dejen dudas acerca de si un decreto delegado constituye un ejercicio de la facultad conferida; y cuando las bases de la ley delegante no generan esas dudas, pero son demasiado amplias o indeterminadas.

\section{Distintos recaudos que los decretos delegados deben satisfacer}

Ese es un modo aceptable, a mi manera de ver, de despejar la confusión sobre las condiciones que activan la doctrina de la Corte. Conviene examinar ahora qué debe probarse, una vez que esas condiciones están configuradas, para que el decreto sea constitucional.

La doctrina de la Corte exige que el interesado muestre que el decreto satisface ciertos recaudos porque, de lo contrario, es inconstitucional. Pero no es claro a primera vista tampoco qué recaudos debe satisfacer.

Así, la Corte sostuvo que

cuando las bases estén formuladas en un lenguaje demasiado genérico e indeterminado, la actividad delegada será convalidada por los tribunales si el interesado supera la carga de demostrar que la disposición dictada por el Presidente es una concreción de la específica política legislativa que tuvo en miras el Congreso al aprobar la cláusula delegatoria de que se trate. 
Como se ve, la Corte distingue entre las bases y la política legislativa. Si el interesado muestra que el decreto concreta la política legislativa, el decreto es válido aunque la base sea demasiado genérica o indeterminada. Si la base no es demasiado genérica o indeterminada, se supone, el decreto es válido independientemente de la política legislativa.

Esa idea, sin embargo, está en tensión con otra mantenida por la propia Corte unos renglones antes, a saber, que la eficacia de la delegación es un asunto de interpretación restrictiva.

Recuérdese que la Corte sostuvo también explícitamente que ha optado por una de las alternativas al enfrentar el problema de las bases demasiado indeterminadas, esto es, interpretar restrictivamente la eficacia de la delegación. Por eso la Corte afirmó que había dos opciones:

o bien anular la ley delegatoria por no fijar un lineamiento inteligible, o bien interpretar muy restrictivamente la eficacia de la delegación y, por lo tanto, limitar las posibilidades de que el acto en cuestión pueda encontrar apoyo en la delegación excesivamente vaga.

La Corte ha reafirmado en otros pronunciamientos la idea de la interpretación restrictiva. En un fallo reciente sostuvo que

no resulta suficiente invocar una ley genérica o poco específica para justificar que la subdelegación se encuentra permitida. En este punto, cabe recordar que el instituto de la delegación es de interpretación restrictiva, tanto cuando ocurre entre órganos de la administración (artículo 3 de la ley 19549), como cuando se trata de delegación de facultades de un Poder del Estado a otros, en particular, cuando se delegan facultades legislativas en órganos del Poder Ejecutivo, en tanto se está haciendo excepción a los principios constitucionales de legalidad y división de poderes (Fallos 326:2150; 4251) .

La interpretación restrictiva se emplea normalmente, en el derecho en general, de tres maneras diferentes. Se la usa, en ocasiones, para

${ }^{9}$ CS, 03/07/2012, "YPF S.E. c/Esso SAPA s/proceso de conocimiento", cons. 6. Firman la sentencia, que no tiene disidencias, los jueces Highton de Nolasco, Maqueda, Petracchi y Fayt. 
identificar el contenido de las normas en juego. En este caso, la idea es que deben interpretarse las normas relevantes literalmente, de modo que no abarquen más casos que los consignados en su sentido literal. En otros casos se emplea la interpretación restrictiva para establecer si un determinado caso individual satisface las condiciones fijadas en la norma ya identificada ${ }^{10}$ de modo que, ante la duda de si el caso encuadra en la norma, debe suponerse que no lo hace. Por ejemplo, en otro ámbito completamente diferente, si hay dudas acerca de si la actuación de una de las partes en un pleito bloquea la declaración de caducidad de instancia, entonces debe asumirse que las condiciones para declararla no están satisfechas ${ }^{11}$. Por último, a veces se emplea la noción de interpretación restrictiva para cumplir simultáneamente las dos funciones que se acaban de describir.

Un modo de reconstruir la doctrina de la Corte consiste en sostener que exige interpretar restrictivamente tanto las bases como los decretos delegados ${ }^{12}$. Así, la doctrina diría que las bases deben ser identificadas mediante una interpretación literal, y que el interesado debe probar en caso de duda (es decir, cuando hay dudas acerca de si un decreto delegado es consistente con las bases) que el decreto delegado es consistente con las bases.

${ }^{10}$ La noción de caso individual, por contraste con la noción de caso genérico, alude a una situación concreta (real o imaginaria) que debe encuadrarse en el antecedente de alguna norma o standard (el caso genérico) si es que uno quiere establecer su calificación deóntica. Cfr. Alchourrón y Bulygin, Introducción a la metodología de las ciencias jurídicas y sociales, ed. Astrea, Buenos Aires, 1998, pág. 58 .

${ }^{11}$ Fallos 329:3800; 324:1992; 323:3204, entre otros.

${ }^{12}$ Varios autores ven la doctrina de "Colegio Público de Abogados" como fijando una regla de interpretación restrictiva, aunque sin precisar exactamente en qué consiste. Cfr. Gelli, María Angélica, "Control estricto en la delegación legislativa. En el caso 'Colegio Público de Abogados de la Capital Federal'", Sup. Const. 2008 (diciembre), 38 - LA LEY 2009-A, 161; Thury Cornejo, Valentín, "Subdelegación legislativa y ratificación del Congreso en una sentencia cautelar de primera instancia", publicado en Sup. Const. 2010 (marzo), 69 - LA LEY 2010-B, 514; Campoletti, Federico, "La delegación legislativa en la jurisprudencia de la Corte", La Ley online, Sup. Adm. 2010 (agosto), 172. 
En definitiva, hay dos ideas sobre qué debe probar el interesado para que el decreto delegado sea constitucional. Son dos ideas bien diferentes. No es lo mismo tener que mostrar que el decreto delegado es una concreción de la política legislativa que estaría detrás de la ley delegante, que tener que mostrar que es consistente con las bases, interpretadas literalmente, en caso de duda.

\section{La ambigüedad de la doctrina de "Colegio Público de Abogados": dos reglas}

Una vez que se despeja cierta perplejidad inicial de la doctrina de la Corte, pueden distinguirse, según se ha visto, dos condiciones que activarían el control de constitucionalidad de los decretos delegados. Son dos condiciones distintas. La primera es la situación en que las bases son tales que dejan dudas acerca de si un decreto delegado constituye un ejercicio de la facultad conferida (e.g. porque las bases están redactadas de modo oscuro). La segunda tiene lugar cuando no hay tales dudas, pero las bases son demasiado genéricas o excesivas. He intentado mostrar también que, una vez activada la doctrina, hay dos ideas muy diferentes sobre qué debe probar el interesado para que el decreto delegado sea constitucional. O bien debe mostrar que el decreto delegado es una concreción de la política legislativa que estaría detrás de la ley delegante, o bien debe superar el test de la interpretación restrictiva: tiene que mostrar que el decreto es consistente con las bases, interpretadas literalmente, en caso de duda.

Hay en definitiva, en la doctrina de la Corte, dos tesis distintas sobre cuándo se activa la doctrina, y dos tesis distintas acerca de qué debe probarse una vez activada la doctrina.

Si se combinan estas alternativas surgen cuatro reglas diferentes. De manera que la doctrina de la Corte puede ser interpretada como proponiendo no una, sino cuatro reglas sobre cómo juzgar la constitucionalidad de un decreto delegado. Las reglas son éstas:

a) cuando las bases de la ley delegante son tales que dejen dudas acerca de si un decreto delegado constituye un ejercicio de la facultad conferida, tanto las bases como el decreto delegado deben 
considerarse de interpretación restrictiva: ante la duda acerca de si es consistente con las bases (interpretadas literalmente), el decreto es inconstitucional.

b) si las bases son demasiado genéricas (aun si interpretadas literalmente y aunque no haya dudas acerca de si el decreto encuadra en las bases), tanto la ley como el decreto delegado deben considerarse de intepretación restrictiva: ante la duda de si es consistente con las bases (interpretadas literalmente), el decreto es inconstitucional.

c) si las bases de la ley delegante son tales que dejen dudas acerca de si un decreto delegado constituye un ejercicio de la facultad conferida, debe establecerse si el decreto delegado es una concreción específica de la política legislativa.

d) si las bases de la ley delegante son demasiado genéricas (aun si interpretadas literalmente y aunque no haya dudas acerca de si el decreto encuadra en las bases), debe establecerse si el decreto delegado es una concreción específica de la política legislativa.

A mi manera de ver, las opciones (a) y (d) son los modos naturales de interpretar la doctrina de la Corte.

La opción (b) es claramente inconsistente. Si no hay dudas acerca de que el decreto encuadra en las bases, constituye un sinsentido afirmar que ante la duda el decreto es inconstitucional. Y la opción (c) no parece tener mucho sentido tampoco: si hay dudas, parece que ello no tiene mucha relación con una política legislativa que el decreto no ha concretado.

En definitiva, un modo aceptable de reconstruir la postura de la Corte es considerar que ha dejado sentadas dos reglas distintas. Si las bases de la ley delegante son tales que dejen dudas acerca de si un decreto delegado constituye un ejercicio de la facultad conferida, tanto las bases como el decreto delegado deben considerarse de interpretación restrictiva: ante la duda acerca de si es consistente con las bases (interpretadas literalmente), el decreto es inconstitucional. Y si las bases de la ley delegante son demasiado genéricas (aun si interpretadas 
literalmente y aunque no haya dudas acerca de si el decreto encuadra en las bases), debe establecerse si el decreto delegado es una concreción específica de la política legislativa.

\section{El problema con las dos reglas}

En "Colegio Público de Abogados", entonces, parece que la Corte ha propuesto en realidad dos reglas distintas. Pero ¿son aceptables estas dos reglas?

La segunda regla se basa, como resultará claro, en una distinción entre las bases y la política legislativa. Esa distinción es problemática, a mi manera de ver, por varias razones.

En primer lugar, aunque las bases pueden identificarse fácilmente consultando la ley delegante, la Corte no suministra indicaciones acerca de qué es ni de cómo identificar la política legislativa. Tampoco es claro cuál es la relación entre las bases y la política legislativa. Presumiblemente, la política legislativa sería, como mínimo, el propósito perseguido al dictar la ley delegante. Pero es posible que muchas de las leyes delegantes que generaron la necesidad de establecer la doctrina de "Colegio Público de Abogados" no tengan ninguna otra política legislativa detrás. Esas leyes delegantes solo tienen como propósito delegar irrestrictamente. Eso es justamente lo que la Corte quiere controlar al crear la doctrina. Pero entonces cualquier decreto delegado problemático es una concreción específica de la política legislativa.

En segundo lugar, la doctrina parece apartarse de la norma constitucional. El art. 76 de la Constitución Nacional claramente dice que la delegación solo es admisible si se ejerce dentro de las bases. No establece ningún requisito adicional. En momento alguno se alude a la "política legislativa"13.

${ }^{13}$ Algunos autores afirman que mencionar la idea de "política legislativa" constituye un error de interpretación de la voluntad del constituyente. Así, Salvadores de Arzuaga sostiene que "las bases de delegación no pueden identificarse con la llamada política legislativa que conceptualmente ha venido desarrollando la Corte para justificar la delegación legislativa ante el vacío constitucional, tampoco con el intelligible standard de la Corte Norteamericana", y lo hace en base a una interpretación de la discusión entre 
En tercer lugar, hablar de "política legislativa" es una reminiscencia de la doctrina sentada en "Cocchia" (Fallos 316:2624), un caso tratado por la Corte Suprema en su anterior integración, antes de la reforma constitucional (es decir, cuando no estaba prevista expresamente la facultad de dictar decretos delegados). Allí se discutía la constitucionalidad de un decreto que derogó una convención colectiva de trabajo en el marco de una supuesta emergencia. Según la mayoría, se trató de una "delegación impropia", y la facultad fue ejercida dentro de la política legislativa, expresada en diversas leyes y tratados. La Corte sostuvo entonces que la política legislativa debía estar contenida en un bloque de legalidad y expresada en un programa de gobierno disperso en un número amplio de leyes y tratados. "Cocchia" fue criticado por extender al máximo la facultad presidencial y por ser poco claro ${ }^{14}$. Es algo paradójico, en ese marco, que la Corte actual, en "Colegio Público de Abogados", traiga a colación una doctrina similar a la de "Cocchia".

los convencionales constituyentes (op. cit.). Quiroga Lavié sostiene que la noción de "bases" fue tomada de la Constitución Española, que no hace mención alguna a la idea de política legislativa. Cfr. "El Poder Legislativo en la nueva Constitución" en Manuel Aragón, Andrés Betancor y otros: La Constitución Argentina de Nuestro Tiempo, Ed. Ciudad Argentina, Bs. As., 1996, pág. 153. Veáse también "Constitución de la Nación Argentina Comentada", Ed. Zavalía, Bs. As., 1996, pág. 499. Otros sostienen que el constituyente toma el concepto bases de delegación para hacer referencia a la noción de política legislativa (cfr. Alfonso Santiago (h.) y Thury Cornejo Tratado sobre la delegación legislativa, Buenos Aires, Abaco, 2003, pág. 178, pág. 415). El argumento del texto es independiente de esta discusión doctrinaria. Lo cierto es que la Corte misma distingue entre política legislativa y las bases. Eso no significa que la Corte no crea que no estén relacionadas (aunque no explica cuál sería la relación). Presumiblemente lo están. El punto es que la Corte distingue entre bases y política legislativa de un modo (i.e. "si las bases son indeterminadas, entonces hay que acudir a la política legislativa") que implica que ha introducido una distinción que no aparece en el texto constitucional.

${ }^{14}$ Cfr. SANTIAGO, ALFONSO-THURY CORNEJO, VALENTIN, Tratado sobre la delegación legislativa, Buenos Aires, Abaco, 2003, pág. 178; Toricelli, Maximiliano, "Control de las facultades legislativas delegadas", publicado en: LA LEY 2008-F, 566; Mario Cámpora en "Delegación legislativa”, LA LEY, 2006 B, pág. 284. 
Por último, la tesis de "Colegio Público de Abogados" no parece ajustarse a la postura que la propia Corte Suprema considera relevante sobre cómo interpretar el art. 76. La Corte dice explícitamente que el modelo fue tomado del derecho norteamericano, y la doctrina del intelligible standard, según la cual las bases deben proporcionar un criterio claro e inteligible de qué se ha delegado. El derecho estadounidense, que supuestamente es la fuente en la que abreva nuestra Constitución, optó - según la Corte - por interpretar restrictivamente la eficacia de la delegación, no por exigir al interesado probar que el decreto delegado encuadra dentro de un marco normativo (la "política legislativa") distinto del marco que la Constitución prevé (las bases).

En definitiva, la segunda regla que uno puede encontrar en "Colegio Público de Abogados" parece difícil de aceptar. Apela a una idea (la política legislativa) que enfrenta varias objeciones.

La primera regla parece aceptable, por contraste. La idea de que las bases y el decreto deben interpretarse restrictivamente es mucho más clara, y consistente con el texto constitucional. Si el dictado de decretos delegados es el ejercicio de facultades excepcionales, el ejercicio de esa facultad ya es, por razones constitucionales, de interpretación restrictiva.

El problema es que esa regla no constituye un avance significativo para el problema que se pretendía resolver. Pues la regla deja abierta la cuestión de qué hacer con leyes delegantes cuyas bases tienen un contenido claro pero son demasiado genéricas.

\section{Algunas conclusiones y una sugerencia final}

En "Colegio Público de Abogados" la Corte dejó establecida una doctrina para controlar la constitucionalidad de los decretos delegados que, aunque constituye un intento por delimitar el ejercicio de facultades legislativas por el Poder Ejecutivo ${ }^{15}$, es notoriamente confusa. Un modo de reconstruir la doctrina de la Corte que despeja cierta confusión inicial consiste en suponer que ha propuesto en realidad dos reglas.

15 Otros intentos importantes de efectuar esa limitación aparecieron en "Czerniecki" (Fallos 318:137), "Selcro" (326:4251) y "Federación de Empresarios de Combustibles" (Fallos 328:940). 
Una de ellas establece que, si las bases de la ley delegante son demasiado genéricas (aun si interpretadas literalmente y aunque no haya dudas acerca de si el decreto encuadra en las bases), debe establecerse si el decreto delegado es una concreción específica de la política legislativa.

Esta regla es, a mi manera de ver, difícil de aceptar. La noción de política legislativa no está prevista en la Constitución, es notoriamente imprecisa, alejada de la supuesta fuente del texto constitucional y, posiblemente, inútil (pues no puede servir como criterio para distinguir entre decretos válidos e inválidos).

La otra regla parece aceptable, por contraste. La regla dispone que, si las bases de la ley delegante son tales que dejen dudas acerca de si un decreto delegado constituye un ejercicio de la facultad conferida, tanto las bases como el decreto delegado deben considerarse de interpretación restrictiva: ante la duda acerca de si es consistente con las bases (interpretadas literalmente), el decreto es inconstitucional. La regla es aceptable porque la idea de que las bases y el decreto deben interpretarse restrictivamente es mucho más clara, y consistente con el texto constitucional.

El problema es que esa regla no constituye un avance significativo para el problema que se pretendía resolver. Pues uno no sabe cómo debe evaluarse la constitucionalidad de leyes delegantes cuyas bases tienen un contenido claro pero son demasiado genéricas.

El punto realmente problemático estriba, entonces, en establecer qué recaudos deben satisfacer los decretos frente a bases de la ley delegante claras pero demasiado genéricas. Ese trabajo está todavía por hacerse.

Quisiera formular una sugerencia breve, para terminar, sobre cómo podría comenzar a sortearse lo que considero el principal obstáculo para hacer ese trabajo.

La caracterización de la ley delegante en términos de bases "demasiado genéricas o indeterminadas" presupone que hay un standard de comparación, un modelo de ley delegante lo suficientemente determinada que funciona como parámetro. La Corte no ha dicho en "Colegio Público de Abogados", por ejemplo, por qué la ley delegante que allí consideró es "demasiado genérica". La pregunta natural es: ¿demasiado genérica comparada con qué? 
Cualquier elaboración de la regla sobre cómo juzgar la constitucionalidad de leyes delegantes con bases demasiado genéricas debe responder a esa pregunta. Ese es el primer y quizás principal obstáculo que debería sortearse. Una sugerencia en esa línea es la siguiente.

$\mathrm{El}$ art. 76 de la Constitución distingue entre las materias determinadas de la delegación y las bases de la ley delegante. Se sigue de ello que la ley delegante debe contener una indicación sobre las materias de administración o emergencia pública. Adviértase que debe tratarse de materias determinadas. Es decir, no basta que la ley delegante enuncie "materias de administración". Debe ser un asunto incluido en esa materia, claramente especificado. La ley delegante debe también contener una indicación sobre las bases. Como las bases son distintas de las materias de la delegación, las bases no pueden sino consistir en algún tipo de indicación sobre cómo legislar en esos asuntos ya definidos. Y una indicación sobre cómo legislar en ciertos asuntos ya definidos implica, por razones conceptuales, la idea de ciertos límites: debe legislarse de cierto modo en esos asuntos. Eso como mínimo puede requerirse.

En ese marco, parece claro que las bases cuentan como demasiado genéricas o indeterminadas si el límite que fijan es un límite que ya viene impuesto de todos modos, por otras normas. Ese es un ejemplo claro de una ley cuyas bases no ponen límite alguno. $\mathrm{O}$, en palabras de la Corte, de una ley delegante sin bases.

La ley juzgada en "Colegio Público de Abogados" puede ser vista como un ejemplo de bases demasiado genéricas e indeterminadas en ese sentido. La ley dice que delega facultades al Poder Ejecutivo para derogar normas "con el objeto exclusivo de dar eficiencia a la administración". Según parece, la idea es que pueden derogarse normas para promover la eficiencia siempre que eso no colisione con otros valores (de allí la idea de "objeto exclusivo"). Pero cualquier actividad legislativa debe dar eficiencia a la Administración en ese sentido. No hay diferencia alguna entre decir eso y no decirlo. Las bases de esa ley delegante no fijan, en realidad, ningún límite.

Lo anterior constituye una sugerencia sobre cómo comenzar a hacer más precisa la idea de una ley delegante con bases claras pero 
"demasiado genéricas e indeterminadas". La indicación es modesta, por cierto, y la idea debe ser completada. El siguiente paso es intentar responder a la pregunta de cómo deben estar definidos esos límites. Hay muchas maneras de definir los modos en que debe legislarse. Por ejemplo, un límite sobre cómo legislar en ciertos asuntos puede consistir en una indicación de los objetivos que esa legislación debe lograr (valores que debe promover, resultados que debería apuntar a obtener, etc.). Otro límite puede ser una indicación sobre qué cosas no hacer. Otro límite puede consistir en dar varias alternativas entre las cuales decidir. Hay muchos más. Debe entonces proponerse un criterio sobre qué tipo de límites se deben fijar las bases. Ese trabajo aún está por hacerse. 